\title{
A Structural Model Predicting Arab American's Attitudes towards Mental Health Services from Ethnic Identity, Acculturation, and Spirituality
}

Balesh C ${ }^{1}$, Gamst G ${ }^{1^{*}}$, Meyers LS ${ }^{2}$, Der-Karabetian A $^{1}$ and Elias $\mathbf{C}^{3}$

${ }^{1}$ Department of Psychology, University of LaVerne, California, USA

${ }^{2}$ Department of psychology, California State University, Sacramento, USA

${ }^{3}$ Clinical Psychologist, Pomona, California, USA

\begin{abstract}
Objective: The present study was based on the Multicultural Assessment-Intervention Process (MAIP) framework and examined the effects of acculturation, ethnic identity, and spirituality on Arab American mental health service utilization attitudes.

Methods: Based on a convenience sample of 298 Arab American adults, a structural model was configured with ethnic identity directly predicting both Heritage and Mainstream Acculturation. Each of these was proposed to both directly predict the willingness to seek psychological services as well as indirectly through spirituality.

Results: The results showed that greater levels of ethnic identity were associated with more acculturation for both the heritage and mainstream domains. In turn, greater levels of both heritage and mainstream acculturation stategies were predictive of higher levels of individuals being more receptive to seeking psychological help. However spirituality did not appear to be related to the willingness to seek psychological services.

Conclusions: It appeared that Arab American mental health help-seeking attitudes were predicted by ethnocultural variables as generally described by the MAIP model. Implications for future Arab American research were discussed.
\end{abstract}

Keywords: Arab American; MAIP model; Acculturation; Ethnic identity, Spirituality; Help-seeking

\section{Introduction}

The present study examined Arab American mental health helpseeking attitudes by means of a structural equation model with ethnic identity directly predicting Heritage and Mainstream Acculturation. Both of these acculturation latent variables were proposed to both directly predict the willingness to seek psychological services as well as indirectly through spirituality. Understanding the factors that contribute to utilization and non-utilization of mental health services by Arab Americans will help to foster better mental health service delivery to this population and its community. Toward this end, we review the mental health help-seeking literature as it pertains to Arab Americans. Then, using part of the Multicultural Assessment-Intervention Process (MAIP) framework, we briefly review the literature on three potenitally important predictors of Arab American help-seeking.

\section{Help-seeking attitudes and behaviors}

Help seeking is typically viewed as a multi-stage process that includes experiencing a health (or emotional) problem, perceiving the need for professional help, evaluating the cost and benefits of treatment, and engaging in some form of action [1]. One critical commonality that underlies much of this literature is perceived mental illness stigma, both public and personal [2,3]. [4] suggested three stages of mental health help-seeking that Muslim Arab Americans (and by extension other Arab Americans) go through when considering treatment: problem awareness, making a help-seeking decision, and service selection. Obstacles to these various stages that would ordinarily lead to seeking help are driven by Arab American cultural beliefs, values, and norms. Complicating this three-stage model is the observation by Khan [5] that most Arab Americans who experience distress tend to seek help from religion, religious leaders, and family and friends. Thus, many Arab Americans when experiencing mental health challenges will first utilize a variety of community ethnic Arab traditional healing resources prior to seeking help from the behavioral healthcare system [6].

Arab American traditional healers tend to take an active personal role in guiding, instructing, and suggesting courses of action, including engagement of family authorities as opposed to more formalized and detached mental health treatment [7]. Several advantages of traditional healing systems over formal behavioral health services include: nonstigmatizing cultural practices, management of counter-transference issues, community and familial collaborations, and using culturally based idioms of distress [6]. Challenges to traditional healing methods are that many of these religious leaders may not be qualified or sufficiently knowledgeable to provide mental health services [6]. Recent empirical evidences [8] suggest that both Christian and Muslim Arab Americans prefer religious leaders to mainstream community mental health services.

Challenges to Arab American help-seeking processes include Arab social norms concerning family orientation and fatalism, and views about mental health social stigma and disclosure. For example, Arab American families often provide a form of collective social support and may even serve as a proxy for professional intervention services [6] Mental health help-seeking may also be influenced by a religious

*Corresponding author: Gamst G, Professor, Department of Psychology, University of La Verne, USA, Tel: 909-448-4176; E-mail: ggamst@laverne.edu

Received May 18, 2018; Accepted May 28, 2018; Published June 10, 2018

Citation: Balesh C, Gamst G, Meyers LS, Karabetian AD, Elias C (2018) A Structural Model Predicting Arab American's Attitudes towards Mental Health Services from Ethnic Identity, Acculturation, and Spirituality. J Ment Disord Treat 4 : 162. doi: $10.4172 / 2471-271 X .1000162$

Copyright: $(2018$ Balesh C, et al. This is an open-access article distributed under the terms of the Creative Commons Attribution License, which permits unrestricted use, distribution, and reproduction in any medium, provided the original author and source are credited. 
fatalistic viewpoint that some traditional Arab Americans operate under suggesting that emotional and physical problems are due to "God's will" and are therefore outside of an individual's control [9]. Such attitudes may foster symptom toleration and/or acquiescence thereby diminishing mental health help-seeking behaviors [10]. Accompanying Arab American collective orientation to mental health challenges is the issue of perceived social stigma and disclosure. Some traditional Arab Americans may perceive mental health help-seeking as either a threat or an act of family disloyalty [11]

Little published research exists on Arab American mental health help-seeking attitudes. Amri and Bemak [12] reported qualitative data suggesting that among recent Muslim immigrants to the U.S., perceived stigma of mental illness and treatment and cultural mistrust of the Western mental health system remain as major barriers to this populations' treatment decision. On the other hand, several crosscultural studies have addressed this issue. Savaya [13] studied the under-utilization of mental health services by Arab females in Jaffa (a mixed Arab-Jewish ethnic section of Tel Aviv), and suggested that Arab women preferred dealing with family problems within the nuclear family as opposed to seeking help from professionals. Al Darmaki [14] examined United Arab Emirates college students' help-seeking attitudes about mental health services on campus, indicating that while participants displayed "slightly positive" attitudes toward seeking help, they preferred non-professional sources of help such as family and friends. Moreover, Al-Krenawi et al. focused on help-seeking behaviors and attitudes among Arabs from Egypt, Kuwait, Palestine, and Israel, and found that nationality, gender, and education all influenced helpseeking behaviors and attitudes.

Due in part to the lack of empirical research on Arab American mental health service help seeking, the MAIP model [15] was utilized to provide a cultural contextualization in the selection of three constructs (ethnic identity, acculturation, and spirituality) that may predict Arab American mental health help seeking attitudes. Through seven culturally sensitive phases, the MAIP specifies cultural factors that influence behavioral health outcomes including mental health helpseeking attitudes. MAIP component phases include culturally sensitive intake contact (initial screening interview), client match preference (cultural, gender, language, etc.), multicultural status assessment (acculturation, ethnic identity, perceived discrimination, etc.), provider self-perceived cultural competence and multicultural training, ethnicspecific and/or general interventions, and clinical outcome and service satisfaction assessment [16]. The Multicultural Status Assessment phase of the MAIP, and not the entire model, provides the current study with a more nuanced predictive focus of mental health service help seeking for Arab Americans, as opposed to the broader issues of mental health service delivery that the entire MAIP formulation addresses. This MAIP component provides the theoretical scaffolding for the present study.

Initial empirical research with the MAIP has examined the clientpractitioner ethnic/racial match construct [17], acculturation and ethnic identity [18] and practitioner self-reported cultural competence $[19,20]$. More recent work has expanded MAIP domains to include cross-cultural implications [21] and cultural shifting as a coping mechanism [22,23]. Attitudes toward mental health help-seeking among Arab Americans can also be considered within the multicultural expansion of the MAIP framework.

Using the MAIP model as a conceptual framework, we identified the constructs of acculturation, ethnic/racial identity, and spirituality as potential contributors to Arab American attitudes toward mental health service utilization. From this, we configured a structural model that explored the predictive and mediation effects of these variables on Arab American help-seeking attitudes. These constructs are reviewed in the following sections.

\section{Arab American ethnic/racial identity}

Arab American ethnic/racial identity appears to be influenced by multiple factors [24], and the complexities it involves sometimes lead to a paradoxical positioning within U.S. society [25]. Naber has argued that four critical paradoxes shape Arab American identity development. First, Arab Americans belong to complex and diverse communities but are often portrayed in a monolithic way in popular media. Second, Arab Americans are often simultaneously characterized as White Americans and as non-White Americans [26]. Third, Arab Americans are characterized according to Islam (religion) rather than phenotype (biology). Lastly, the interaction between Arab American religious identity and U.S. racial identity helps to produce a unique and sometimes conflicting configuration [25].[27] also has noted that the events of 9/11 have impacted the collective ethnic identity of many Arab Americans. Triggered by these events, issues of xenophobia, racism, and stereotype have interacted, and have served to reinforce positive and negative attitudes already present in U.S. society.

Fakih [28] examined the effects of ethnic identity and perceived discrimination on psychological well-being. Perceived discrimination was strongly associated with diminished well-being particularly among participants with low ethnic identity. Sheldon et al. [29] studied the relationship of ethnic identity (as measured by the original version of the Multigroup Ethnic Identity Measure (MEIM), [30] with three wellbeing subscales (self-acceptance, purpose in life, and personal growth); their multiple regression results indicated that at least one of the MEIM subscales significantly predicted the well-being subscales among the Arab American participants. Further, evidence from Nassar-McMillan, et al. [31], Amer and Hovey [32] suggest strong ethnic identity differences between minority Muslim and majority Christian Arab Americans. Muslim Arab Americans tended to have stronger ethnic identity than did Christian Arab Americans who were more likely to identify with mainstream acculturative norms.

Arab American identity is complex and multivariate. Due in part to this complexity and expectations based on the MAIP framework, it is hypothesized that Arab American ethnic identity will directly predict both Heritage and Mainstream Acculturation, which in turn will positively predict mental health help-seeking attitudes.

\section{Arab American acculturation}

The current process of acculturation for Arab Americans, as is true for other ethnic/racial minorities, is not a simple unidirectional process of adapting to White American mainstream culture [33]. Rather, it reflects bidirectional processes of the acculturating individuals simultaneously sustaining affiliation to their culture of origin (heritage acculturation) and their new culture (mainstream acculturation [34,35]. Acculturation strategies [36] employed by Arab Americans (i.e., separation, assimilation, marginalization, integration) represent multidimensional processes that are motivated by generational status, length of residence in the U.S., religious affiliation (Christian, Muslim), and perceived discrimination [37]. Acculturative change occurs for Arab American individuals as well as their families, and results in transformation of language, behaviors and identity [38].

A few studies have examined acculturation processes on various mental health outcomes for Arab Americans. [35] examined the effects 
of acculturation, acculturative stress, and religiosity on psychological adjustment among a sample of Muslim Arab American adolescents. Their standard multiple regression results indicated that decreases in heritage acculturation (i.e., separation acculturative strategies) and increases in acculturative stress statistically significantly predicted psychological problems. [73] studied Arab immigrants' acculturation strategies and satisfaction with life in the U.S. Their findings indicated that additional time in the U.S., early age of immigration, non-visitation of their country of origin, and Christian identification were associated with higher levels of assimilation and integration acculturation strategies and greater satisfaction with life in the U.S.

Amer and Hovey examined socio-demographic factors that influenced Arab American acculturation strategies and mental health patterns, measuring such factors as Arab ethnic identity, acculturation strategy, acculturative stress, family functioning, religiosity, and depressive symptoms. They observed that older participants were more likely to engage in Arab ethnic practices but that religious commitment was not a statistically significant predictor of participants' acculturation strategy and mental health practices. Female participants indicated higher levels of Arab ethnic practices and were more intrinsically religious than their male counterparts. Amer and Hovey also reported that Arab Americans who were less likely to participate in ethnic practices tended to obtain higher levels of education. Additionally, they found that Arab American Christians who adopted separated or marginalized acculturation strategies dealt with more acculturative stress and depression as compared to Arab American Christians who utilized more assimilated or integrated acculturation strategies.

Aprahamian et al. [39] examined acculturation strategy and mental health among a sample of Arab Americans through the 2003 Detroit Arab American Study. They measured participants' psychological distress, acculturation, and perceived discrimination, and reported that gender, age, income, education, and early age at migration but not type of acculturation strategy predicted Arab American mental health.

Generally, it appears that the acculturation and/or enculturation experiences of Arab Americans, while being partly unique, also share many commonalities and saliencies with other ethnic/racial groups who have immigrated to the U. S [40] Based in part on the previous literature review and expectations from the MAIP model, it is hypothesized that both heritage and mainstream acculturation will positively mediate ethnic identity in the prediction of Arab American mental health help-seeking.

\section{Arab American religiosity and spirituality}

Arab American religiosity (one's involvement in religious activities like prayer and service) and spirituality (personal beliefs and values) are sometimes inseparable constructs because of their linkage to Arabic culture and identity [41,42]. Much of the limited research in this domain tends to dichotomize Arab Americans into Christian (Orthodox, Roman Catholic, Protestant) and Muslim (Sunni, Shi'a) categories that may gloss over important distinctions among denominations. While Arab Americans represent a diversity of religious affiliations, the positive value of religion and its protective role appears to be a shared commonality. For example, when examining ethnic identity, both Christian [43] and Muslim [44] Arab Americans consider their religion to be salient. For many Arab Americans (both Christian and Muslim) religiosity influences and reinforces much of their cultural identity and practice $[45,46]$ However, while the importance of religiosity to most Arab Americans is apparent, there continues to be an inconsistent pattern of results concerning the effects of religious affiliation (Christian and Muslim) on various measures of psychological functioning. For example, Christian Arab Americans were more likely to adopt mainstream acculturative practices, feel greater levels of life satisfaction, experience more success in achieving their acculturation goals, and indicate greater interpersonal openness than Muslim Arab Americans Conversely, Muslim Arab Americans appear to have higher levels of Arab ethnic identity and higher levels of perceived discrimination [47] than Arab American Christians. Alternatively, other studies have shown no appreciable differences between Christian and Muslim Arab Americans on post 9/11 discrimination [48], family cohesion, well-being [49] and psychological distress [50]. Some of these differences (or lack thereof) may be a function of Christian Arab Americans experiencing greater social acceptance since they share the majority American religious orientation [51] variations in methodology and sample selection [52].

Given the importance of spirituality for most Arab Americans, this construct is expected to mediate the effects of Heritage and Mainstream Acculturation in the prediction of Arab American mental health helpseeking.

\section{The present study}

The present research focuses attention on salient variables assumed to drive some of the dynamics underlying Arab Americans seeking mental health help. Understanding how the important predictors and mediators of help-seeking are employed by this population could help to increase service utilization and reduce access barriers for Arab Americans seeking mental health services. Based in part on the Multicultural Status Assessment component of the MAIP model as well as the extant Arab American multicultural literature [52] it is hypothesized that ethnic identity through heritage and mainstream acculturation, and these latter variables both directly and as mediated by spirituality, will be positively associated with Arab American mental health help-seeking attitudes.

\section{Method}

\section{Sample and participant selection}

The present study utilized data from a convenience sample of 298 Arab American adults, 183 (61.4\%) females and 115 (38.6\%) males. Participants were recruited from the list serves of two southern California universities, Network of Arab American Professionals (NAAP), ACCESS, St. Jude's Maronite Catholic Church, Riverside Lebanese Social Committee, various Arab American student college clubs and professional associations across the U.S., and the Arab Americans Lawyers Association of Southern California. These list serves were specifically targeted for the present study because of their prominence within the Arab American community. Prospective participants were invited to complete an online questionnaire designed to gain a better understanding of the factors that predict Arab Americans' attitudes towards formal mental health services. Participants were informed (online) that their participation was voluntary and that their responses would be anonymous. The present research was approved by the university institutional review board, as an incentive, all participants had a chance to win one of four \$25.00 Target e-gift cards.

Participants' age ranged from 18 to $74,(\mathrm{M}=31.93, \mathrm{SD}=10.92)$. Participant Arab country national origin was Lebanon (22.1\%), Egypt (13.8\%), other/multiple countries (11.7\%), Palestine (11.4\%), Syria (11.1\%), Jordan (7.0\%), Saudi Arabia (3.7\%), Algeria (3.4\%), United Arab Emirates (3.4\%), Iraq (2.7\%), Kuwait (2.0\%), Bahrain (1.7\%), Libya (1.3\%), Morocco (1.3\%), Sudan (1.0\%), Comoros (0.7\%), Tunisia 
Citation: Balesh C, Gamst G, Meyers LS, Karabetian AD, Elias C (2018) A Structural Model Predicting Arab American's Attitudes towards Mental Health Services from Ethnic Identity, Acculturation, and Spirituality. J Ment Disord Treat 4: 162. doi:10.4172/2471-271X.1000162

Page 4 of 9

(0.7\%), Yemen (0.3\%), and Oman (0.3\%). The majority of participants (49\%) identified as second generation Arab American, 45\% as first generation, $5 \%$ as third generation, $2 \%$ as fourth generation, and $1.3 \%$ as fifth generation Arab American. Participants' education included college graduates $(33.9 \%)$, graduate degree $(33.2 \%)$, some college (22.8\%), high school (8.7\%), and less than high school (1.0\%). Participants' religion included, Muslim (40.9\%), Christian (40.3\%), spiritual (4.4\%), atheist (4.4\%), and "other" (7.0\%). Regarding the importance of religion, $39.6 \%$ indicated religion is "very important," 25.5\% "important," 23.2\% "somewhat important," and 11.7\% "not at all important." About two-thirds $65.8 \%$ of the participants had never utilized professional mental health services whereas about a third $34.2 \%$ had sought such services at least once.

\section{Measures}

The online questionnaire contained 70 items composing the following six scales together with demographic questions. The six scales were presented in random order to each respondent.

Demographic questions: The demographic questions contained six items that dealt with the participants' gender, age, Arab nationality, education, generational status, and religious importance.

\section{Predictor and mediator measures}

Multigroup Ethnic Identity Measure Revised: The Multigroup Ethnic Identity Measure-Revised (MEIM-R) [53] is a six-item selfreport measure of ethnic identity. The two three-item subscales, Exploration and Commitment were derived through exploratory and confirmatory factor analyses. Phinney and Ong [53] reported adequate internal consistency, as measured by Cronbach's alpha, for both the Exploration $(\alpha=0.76)$ and the Commitment $(\alpha=0.78)$ subscales. Recent work by Brown [54] demonstrated measurement invariance for the MEIM-R, suggesting it can be utilized to measure ethnic identity across multiple racial and ethnic groups. Items were measured on a 5-point summative response scale that ranged from 1 (strongly disagree) to 5 (strongly agree). For the present study, internal consistency values were 0.82 and 0.85 for Exploration and Commitment, respectively.

Vancouver Index of Acculturation: The Vancouver Index of Acculturation (VIA) [55] is a 20-item bidirectional measure of multigroup acculturation. The VIA is composed of two 10item subscales. The Heritage subscale reflects the culture of birth and upbringing, whereas, the Mainstream subscale reflects the predominant cultural environment. Ryder reported Cronbach's alphas of 0.79 for the Heritage and 0.75 for the Mainstream subscales. More recently [56] reported that the VIA's internal reliability estimates for the Heritage and Mainstream subscales were 0.85 and 0.91 . Items were measured on a 9-point summative response scale that ranged from 1 (strongly disagree) to 9 (strongly agree). For the present study, internal consistency values were 0.89 and 0.85 for Heritage and Mainstream subscales, respectively.

Daily Spiritual Experience Scale: The Daily Spiritual Experience Scale [57] is a 16-item unidimensional self-report measure of an individual's perception of the transcendent (God, the divine) in daily life by examining themes such as compassionate love, mercy, gratitude, awe, and a connection with the divine. Items were measured on a 6-point summative response scale that ranged from 1 (many times a day) to 6 (never), thus the higher the score, the lower the selfreported spirituality. [57] utilizing a principal components analysis, reported a unidimensional component structure with a Cronbach's alpha coefficient of 0.94 . For the present study, internal consistency as measured by Cronbach's alpha was 0.96 .

\section{Outcome measures}

Attitudes Toward Seeking Professional Psychological ServicesShort Form: The Attitudes toward Seeking Professional Psychological Services-Short Form (ATSPPH-SF) is a 10-item unidimensional version of the Fischer and Turner [58] 29-item ATSPPH measure. Items were measured on a 4-point summative response scale that ranged from 0 (disagree) to 3 (agree). Fischer and Farina [59] reported a one-factor exploratory factor analysis solution, with a Cronbach's alpha of 0.84 . For the present study, Cronbach's alpha was 0.78.

Beliefs About Psychological Services: The Beliefs About Psychological Services (BAPS) [60] is an 18-item self-report measure that assesses attitudes and beliefs about seeking psychological services. Items were measured on a 6-point summative response scale that ranged from 1 (strongly disagree) to 6 (strongly agree). Results of an exploratory factor analysis by Ægisdottir and Gerstein [60] suggested a three-factor structure composed of the following subscales and their respective Cronbach's alphas: Intent $(\alpha=0.82)$, Stigma Tolerance $(\alpha=0.78)$, and Expertness $(\alpha=0.72)$. For the present study, internal consistency values were 0.86 for Intent, 0.84 for Stigma Tolerance, and 0.78 for Expertness [62-89].

Marlowe Crowne Social Desirability Scale-Short Form: The Marlowe-Crowne Social Desirability Scale-Short Form (M-CSDSSF) is used to assess the impact of social desirability bias upon self-report instruments. The instrument consists of 13 true/false statements. Zook and Sipps [90] have reported adequate reliability across studies. In the present study, a Cronbach's alpha coefficient of 0.70 was obtained [62].

\section{Results}

\section{Descriptive statistics}

The means, standard deviations, and internal consistency reliabilities for the scale and subscale scores used in the present study are presented in Table 1 . The values are generally in the range of those reported in the literature. All scales and subscales reached a minimally acceptable level of internal consistency of at least 0.70 .

Correlations among demographic variables and key measures are also shown in Table 1. The four measures of mental health help-seeking (ATSPPHSF, BAPS Intent, BAPS Stigma Tolerance, BAPS Expertness) were moderately intercorrelated $(r=0.49$ to $0.61, p<.0001)$. The MEIM-R ethnic identity subscales (Exploration, Commitment) were moderately correlated $(r=0.69, p<0.01)$ as were the VIA acculturation subscales (Heritage, Mainstream) $r=0.46, p<0.01$.

\section{The structural model}

A structural equation model with five latent variables was configured as shown in Figure 1. The latent variable of Seek Psychological Help was established as the outcome variable using as indicators two of the three subscales of the BAPS (Intent and Expertness) and a single measure representing the ATSPPH-SF (Seek). The Stigma Tolerance subscale of the BAPS was originally included as a fourth indicator but it was much less related to the construct than the other three measures and its inclusion resulted in a lower degree of model fit (although the fit was still at an acceptable level).

Ethnic Identity as indicated by the two subscales (Exploration and Commitment) of the MEIM-R was proposed as an exogenous predictor in the model. It was hypothesized that Ethnic Identity would 
Citation: Balesh C, Gamst G, Meyers LS, Karabetian AD, Elias C (2018) A Structural Model Predicting Arab American's Attitudes towards Mental Health Services from Ethnic Identity, Acculturation, and Spirituality. J Ment Disord Treat 4: 162. doi:10.4172/2471-271X.1000162

Page 5 of 9

\begin{tabular}{|c|c|c|c|c|c|c|c|c|c|c|c|c|}
\hline Variable & 1 & 2 & 3 & 4 & 5 & 6 & 7 & 8 & 9 & 10 & 11 & 12 \\
\hline 1.Attitude & & $.61^{* *}$ & $.49^{* *}$ & $.50^{* *}$ & $-0.15^{*}$ & $0.13^{*}$ & -0.06 & $0.14^{*}$ & 0.09 & 0.08 & $0.12^{*}$ & -0.01 \\
\hline 2. Intent & & - & $.14^{*}$ & $.71^{*}$ & $-0.11^{*}$ & 0.05 & -0.04 & $0.23^{* *}$ & $0.17^{* *}$ & $0.25^{* *}$ & $0.26^{* *}$ & 0.05 \\
\hline 3. Stigma Tol & & & - & $.21^{* *}$ & $0.14^{*}$ & -0.03 & -0.09 & 0.1 & 0.05 & 0.04 & 0.06 & -0.03 \\
\hline 4. Expert & & & & - & -0.06 & 0.08 & -0.12 & $0.24^{* *}$ & $0.22^{* \star}$ & $0.28^{* *}$ & $0.26^{* *}$ & -0.02 \\
\hline 5. Gender & & & & & - & $0.24^{* *}$ & 0.03 & -0.04 & -0.03 & -0.08 & 0.1 & $0.12^{*}$ \\
\hline 6. Age & & & & & & - & -0.08 & 0.04 & 0.04 & 0.01 & $0.13^{*}$ & -0.01 \\
\hline 7. Religion & & & & & & & - & -0.11 & -0.12 & $-0.18^{* *}$ & 0.04 & 0.05 \\
\hline 8. Explore & & & & & & & & - & $0.69^{* *}$ & $0.55^{* *}$ & $0.29^{* *}$ & $-0.20^{* *}$ \\
\hline 9. Commit & & & & & & & & & - & $0.65^{* *}$ & $0.28^{* *}$ & $-0.30^{* *}$ \\
\hline 10. Heritage & & & & & & & & & & - & $0.46^{* *}$ & $-0.26^{* *}$ \\
\hline 11.Main & & & & & & & & & & & - & 0.01 \\
\hline \multicolumn{13}{|l|}{ 12. Daily } \\
\hline 13. MCSD-SF & & & & & & & & & & & & \\
\hline
\end{tabular}

Note: Attitude: ATSPPHSF; Intent: BAPS Intent Subscale; Stigma Tol: BAPS Stigma Tolerance Subscale; Expert: BAPS Expertness Subscale; Gender: Participant Gender (Male: 1, Female: 2); Age: Participant Age; Religion: Participant Religion (Christian: 1, Muslim: 2); Explore: MEIM-R Exploration Subscale; Commit: MEIM-R Commitment Subscale; Heritage: VIA Heritage Subscale; Main: VIA Mainstream Subscale; Daily: DSES Scale; MCSD-SF: Marlowe-Crowne Social Desirability-Short Form. * ${ }^{*}<0.05$. ${ }^{* *} \mathrm{p}<0.01$.

Table 1: Correlation coefficients, means, standard deviations, and alphas among variables used to predict help-seeking attitudes among Arab American adults ( $\mathrm{N}=298$ ).

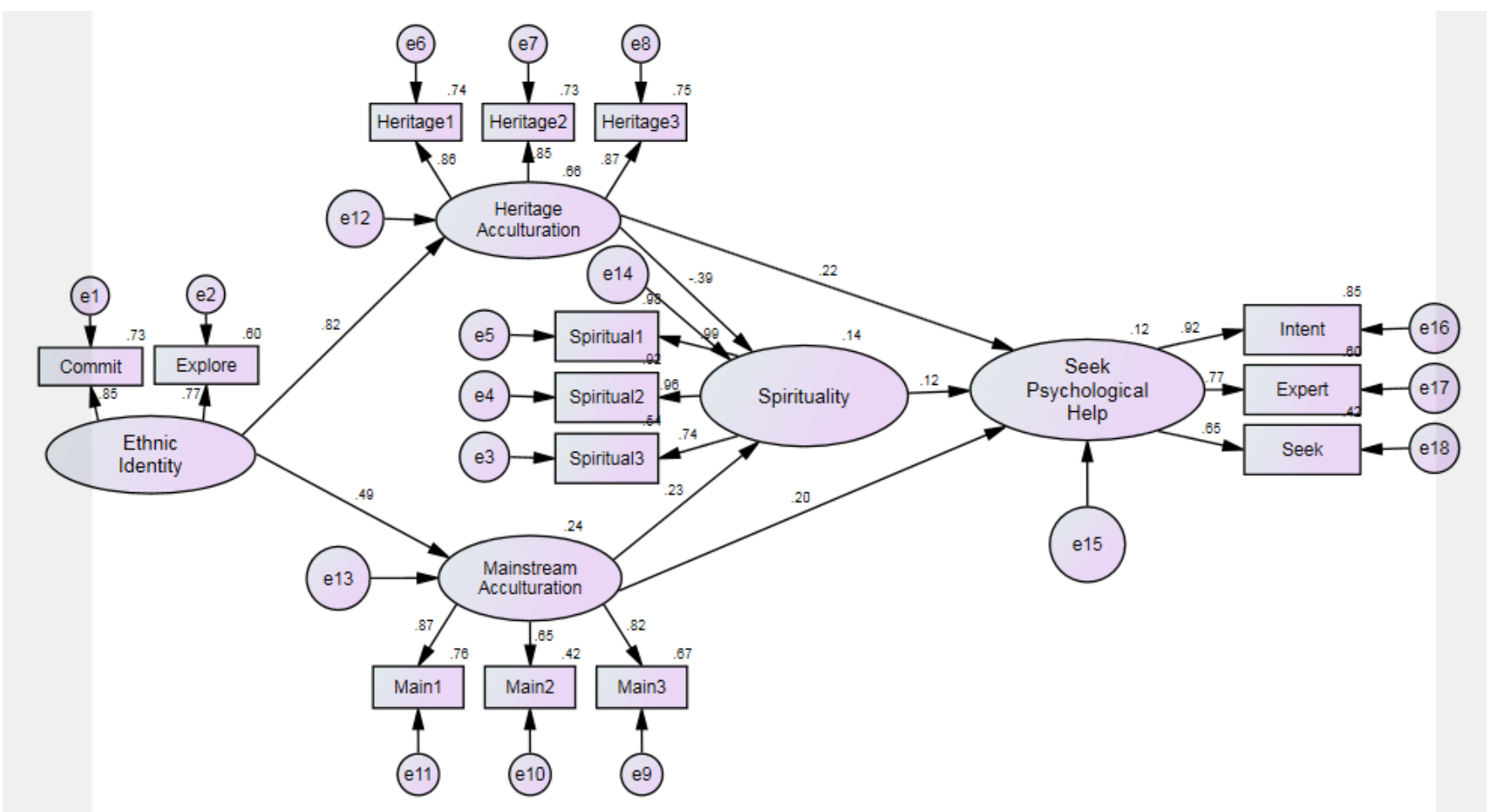

Figure 1: Structural model for seeking psychological help. Latent constructs are shown in ellipses, and observed variables are shown in rectangles.

exert an indirect effect on Seek Psychological Help by acting through the acculturation variables, the Heritage and Mainstream subscales of the VIA. Heritage and Mainstream were each proposed to directly affect Seek Psychological Help as well as to indirectly affect Seek Psychological Help by acting through Spirituality as assessed by the DSES.

The Heritage and Mainstream subscales of the VIA and the DSES each represented a unidimensional construct (supported for our data set by our own preliminary principal axis factor analyses) but it was feasible to convert these measures into latent variables [63] using item parceling [64-68]. To achieve this parceling, the 16 items of the DSES were allocated into three item sets containing 5, 5, and 6 items. Items were assigned to the parcels by grouping those with similar wording together or, where that was not feasible, by random assignment. Item scores in each set were then averaged to obtain an item parcel score, and these three measured variables served as indicators to represent a latent outcome variable of Spirituality.

An analogous but somewhat simpler procedure was used for the Heritage and Mainstream subscales. With each subscale containing nine items, we computed three parcels of three items each. Items were assigned in randomized blocks of three to each parcel based on their magnitude of correlations with the factor in the principal axis analysis. That is, the first set of three items were assigned randomly to each of the 
three parcels, then the second set of three items were assigned in this manner, and then the third.

Analysis of the structural model was performed in IBM SPSS Amos version 25 . The chi square value was statistically significant $(70, N=298)=174.099, \mathrm{p}<0.001$, but the GFI, IFI, TLI, and CFI were $0.925,0.962,0.950$, and 0.961 , respectively, and the RMSEA was 0.071 (90\% CI: 0.058-0.084); these indexes taken together suggested that the model yielded a good fit to the data and explained approximately $67 \%, 24 \%, 14 \%$, and $12 \%$ of the variance of Heritage Acculturation, Mainstream Acculturation, Spirituality, and Seek Psychological Help.

As was the case when we examined it in isolation, Spirituality was not a statistically significant predictor of Seek Psychological Help (standardized path coefficient $=0.116$, unstandardized path coefficient $=0.128, \mathrm{p}=0.072$ ). However,, both Heritage (standardized path coefficient $=0.218$, unstandardized path coefficient $=0.159$, $\mathrm{p}=0.004$ ) and Mainstream Acculturation (standardized path coefficient $=0.200$, unstandardized path coefficient $=0.160, p=0.006$ ) did significantly predict Seek Psychological Help (as they did in isolation). Both Heritage (standardized path coefficient $=-0.393$, unstandardized path coefficient $=-0.261, \mathrm{p}<0.001$ ) and Mainstream Acculturation (standardized path coefficient $=0.231$, unstandardized path coefficient $=0.167, \mathrm{p}<0.001$ ) were also related to Spirituality.

Ethnic Identity significantly predicted both Heritage (standardized path coefficient $=0.815$, unstandardized path coefficient $=1.586, \mathrm{p}<0.001$ ) and Mainstream Acculturation (standardized path coefficient $=0.486$, unstandardized path coefficient $=0.868, \mathrm{p}<0.001$ ). As shown by Aroian tests, the most conservative variation of the Sobel [87] test family, the indirect paths of Ethnic Identity through Heritage Acculturation to Seek Psychological Help $(\mathrm{z}=11.38, \mathrm{p}<0.001)$ and of Ethnic Identity through Mainstream Acculturation to Seek Psychological Help ( $\mathrm{z}=2.55$, $\mathrm{p}=.010$ ) were both statistically significant.

In summary, greater levels of Ethnic Identity were associated with more Acculturation for both the Heritage and Mainstream domains. In turn, greater levels of both Heritage and Mainstream Acculturation were predictive of higher levels of individuals being more receptive to seeking psychological help. However, Spirituality did not appear to be related to the willingness to seek psychological services, although lower levels of Heritage and higher levels of Mainstream Acculturation were associated with increased Spirituality.

\section{Discussion}

The current study examined theimpact of the following Multicultural Status Assessment component variables of the MAIP model: ethnic identity, acculturation, and spirituality, as possible contributors to the prediction of Arab American attitudes toward mental health service utilization. A structural model was built in which we found that greater levels of Arab American ethnic identity (as composed of Commitment and Exploration) predicted increases in both Heritage and Mainstream Acculturation (i.e., Arab American biculturality) which in turn mediated among these individuals an increased willingness to seek mental health services. Interestingly, Spirituality with this sample had little predictive relationship to the seeking of psychological services, even though assimilated acculturation strategies (i.e., low Heritage and high Mainstream Acculturation) was linked to increases in Spirituality.

For the most part, the present findings are in accord and extend previous work examining Arab American attitudes toward mental health services. The Ethnic Identity latent variable, which consists of the MEIM-R subscales Exploration (i.e., the effort to learn about one's ethnic group) and Commitment (i.e., the sense of belonging and connection toward one's ethnic group) predicted both Heritage and Mainstream Acculturation latent variables, which in turn predicted psychological help seeking. These findings of strong ethnic identity association for both Arab American heritage and mainstream acculturation attitudes is congruent with the work of [31] and may reflect the diverse Christian and Muslim participants in the present sample. These findings are particularly salient due to the paucity of published literature that has examined Arab American ethnic identity and mental health helpseeking attitudes and behaviors. [6] Furthermore, these results contrast with inconsistent findings reported with other cultural groups with high levels of ethnic identity indicating both negative and positive attitudes toward seeking mental health services $[69,70]$.

Concerning the predictive effects of acculturation on attitudes toward seeking mental health services, some studies have reported a lack of predictability [71,72] whereas other studies have found acculturation to be a positive predictor [73]. Our results support these latter findings.

Recent work in the health field with Arab Americans underscores these findings. Jadalla and Lee [74] found that bicultural attitudes predicted better physical well-being among Arab Americans, and that Arab Americans who adopted more bicultural or integrated acculturation strategies to American culture reported better mental health. Recently Jadalla et al. [75] found that Arab Americans who were attracted to Arab culture preferred healthier nutritional and stress management practices whereas Arab Americans who adopted assimilated acculturation strategies reported better physical activity practices. It therefore appears that acculturation status among Arab Americans appears to provide subtle influence on health promotion behavior and sometimes on attitudes toward seeking professional mental health services.

Spirituality, as measured by the DSES while did not directly predict help seeking, did mediate the effects of both Heritage and Mainstream Acculturation. Specifically, the combination of relatively low levels of Heritage and high levels of Mainstream acculturation attitudes (i.e., assimilated acculturation strategies) were predictive of increased Spirituality. These findings may indicate that assimilating to mainstream American culture is accomplished for Arab Americans through increased spiritual awareness. The present findings support Ajrouch [77] who found that Arab Americans' religious affiliation was not correlated with psychological well being. The present results contrast with Al-Krenawi and Graham [78] who explored Arab students' attitudes toward professional mental health services and found that Arab Christians were more likely to view mental health services with less stigma, were more personally open, and more likely to utilize mental health services.

Several limitations of the present study can be noted. First, many of the participants were recruited from Arab American professional networks, student organizations, advocacy groups, and social media. Thus, the majority of participants were young adults and tended to be college educated. Future research with a more diverse Arab American sample is warranted to gain a greater understanding of Arab American attitudes about seeking mental health services. A second limitation is that the measuring instruments used to assess ethnic identity, acculturation, and spirituality may not have been sensitive to an Arab American population. Future research should consider using instruments that have been normed with this population. The present research is important because it helps to further our understanding of Arab Americans' mental health help-seeking attitudes. At times, these 
Citation: Balesh C, Gamst G, Meyers LS, Karabetian AD, Elias C (2018) A Structural Model Predicting Arab American's Attitudes towards Mental Health Services from Ethnic Identity, Acculturation, and Spirituality. J Ment Disord Treat 4: 162. doi:10.4172/2471-271X.1000162

attitudes, especially concerns about social stigma, help to constrain Arab Americans from fully utilizing available mental health resources. The theoretical framework that helped to motivate this research was the MAIP model [15-34]. The Multicultural Status Assessment phase of the model postulates the importance of examining issues related to a clinical and non-clinical population's multicultural characteristics in relation to specific outcome variables. Of particular importance to the present study was the multicultural status assessment, which emphasizes the respondents' ethnic identity, acculturation status, and spirituality. These cultural factors embodied in this phase of the MAIP model identified several useful predictor variables that were used to explore Arab American help-seeking attitudes. The MAIP model can serve as a useful framework for future Arab American research regarding mental health service utilization.

\section{References}

1. Wendt D, Shafer K (2016) Gender and attitudes about mental health help seeking: Results from national data. Health \& Social Work 41: 20-28.

2. Eisenberg D, Downs MF, Golberstein E, Zivin K (2009) Stigma and help seeking for mental health among college students. Med Care Res Rev 66: 522-541.

3. Pham AV, Goforth AN, Chun H, Olivo CS, Costa A (2017) Acculturation and help-seeking behavior in consultation: A sociocultural framework for mental health service. Journal of Educational and Psychological Consultation 27: 1-18.

4. Aloud N, Rathur A (2009) Factors affecting attitudes toward seeking and using formal mental health and psychological services among Arab Muslim populations. Journal of Muslim Mental Health 9: 335-347.

5. Khan Z (2006) Attitudes toward counseling and alternative support among Muslims in Toledo, Ohio. Journal of Muslim Mental Health 1: 21-42.

6. Al-Krenaw A, Graham JR (2016) Help-seeking: Traditional and modern ways of knowing, and insights for mental health practice. In: Amer MM, Awad GH (eds.) Handbook of Arab American psychology. Routledge, New York, pp: 263-274.

7. El-Islam ME (1982) Arabic cultural psychiatry. Transcultural Psychiatric Research Review 19: 5-24.

8. Abu-Ras W, Gheith A, Cournos F (2008) The imam's role in mental health promotion: A study of 22 mosques in New York City's Muslim community. Journal of Muslim Mental Health 3: 155-176.

9. Hamda A (2009) Mental health needs of Arab women. Health Care Women Int 30: 593-611.

10. Hamid A, Furnham A (2013) Factors affecting attitude towards seeking professional help for mental illness: A UK Arab perspective. Mental Health Religion, \& Culture 16: 741-758

11. Abudabbeh N, Nydell MK (1993) Transcultural counselling and Arab Americans In: McFadden $\mathrm{J}$ (ed.) Transcultural counselling: Bilateral and international perspectives, American Counselling Association. Alexandria, pp: 261-284.

12. Amiri S, Bemak F (2013) Mental health help-seeking behaviors of Muslim immigrants in the United States: Overcoming social stigma and cultural mistrust. Journal of Muslim Mental Health 7: 43-63.

13. Savaya R (1998) The under-use of psychological services by Israeli Arabs: An examination of the roles of negative attitudes and the use of alternative sources of help. International Social Work 41: 195-209.

14. Al-Darmaki F (2011) Needs, attitudes toward seeking professional help and preferred sources of help among Emirati college students. Journal for International Counselor Education 3: 39-57.

15. Dana RH (1993) Multicultural assessment perspectives for professional psychology. Needham Heights, MA: Allyn \& Bacon

16. Gamst G, Meyers LS (2014) Confirmatory factor analysis of the Acculturation Rating Scale-II Scale 2: The case for measurement of marginality. Hispani Journal of Behavioral Sciences 36: 435-451.

17. Gamst G, Dana RH, Der Karabetian A, Kramer T (2000) Ethnic match an clien ethnicity effects on global assessment and visitation. Journal of Communit Psychology 28: 547-564.

18. Gamst G, Dana RH, Der-Karabetian A, Aragon M, et al. (2002) Effects of Latino acculturation and ethnic identity on mental health outcomes. Hispanic Journal of Behavioral Sciences, 24: 479-505.

19. Gamst G, Dana RH, Der-Karabetian A, Aragon M, Arellano L et al.,(2004) Cultural competency revised: The California Brief Multicultural Competence Scale. Measurement and Evaluation in Counseling and Development 37: 163 183.

20. Keyser V, Gamst G, Meyers LS, Der-Karabetian A, Morrow G (2015) Predictors of self-perceived cultural competence among children's mental health providers. Cultural Diversity and Ethnic Minority Psychology 20: 324-335.

21. Lieberman DA, Gamst G (2015) Intercultural communication competence revisited: Linking the intercultural and multicultural fields. International Journal of Intercultural Relations 48: 17-19.

22. Gamst G, Morales A, Meyers LS, Tolstoy B, Garcia S, et al.(2018) Development and validation of the Latina American Shifting Scale (LASS). Manuscript under review.

23. Johnson JC, Gamst G, Meyers LS, Arellano-Morales L, Shorter-Gooden K (2015) Development and validation of the African American Women's Shifting Scale (AAWSS). Cultur Divers Ethnic Minor Psychol 22: 11-25.

24. Nagel CR, Staeheli LA (2004) Citizenship, identity and transnational migration: Arab immigrants to the United States. Space and Polity 8: 3-23.

25. Naber N (2000) Ambiguous insiders: An investigation of Arab American invisiblility. Ethnic and Racial Studies 23: 37-61.

26. Ajrouch KJ, Jamal A (2007) Assimilating to a white identity: The case of Arab Americans. International Migration Review 41: 860-879.

27. Salaita S (2005) Ethnic identity and imperative patriotism: Arab Americans before and after 9/11. College Literature 32: 146-168.

28. Fakih RR (2013) Ethnic identity among Arab Americans: An examination contextual influences and psychological well-being. Unpublished doctoral dissertation, Wayne State University.

29. Sheldon JP, Oliver GD, Balaghi D (2015) Arab American emerging adults ethnic identity and its relation to psychological well-being. Emerging Adulthood 3: 340-352.

30. Phinney JS (1992) The Multigroup Ethnic Identity Measure: A new scale for use with diverse groups. Journal of Adolescent Research 7: 156-176.

31. Nassar-McMillan SC, Lambert RG, Hakim-Larson J (2011) Discrimination history, backlash fear, and ethnic identity among Arab Americans: Post-9/1 snapshots. Journal of Multicultural Counseling \& Development 39: 38-47.

32. Amer M, Hovey J (2007) Socio-demographic differences in acculturation and mental health for a sample of $2^{\text {nd }}$ generation/early immigrant Arab Americans Journal of Immigrant and Minority Health 9: 335-347.

33. Gordon MM (1964) Assimilation in American Life: The role of race, religion, and national origin, London, UK: Oxford.

34. Gamst GC, Liang CTH, Der-Karabetian A (2011) Handbook of multicultura measures. Thousand Oaks, CA: SAGE.

35. Goforth AN, Oka ER, Leong FTL, Denis DJ (2014) Acculturation, acculturative stress, religiosity and psychological adjustment among Muslim. Journal of Muslim Mental Health: 3-19.

36. Berry JW (2003) Conceptual approaches to acculturation. In: Chun KM, Organista PB, Marin G (eds.) Acculturation: Advances in theory, measurement and applied research Washington, DC: American Psychological Association, pp: 17-37.

37. Amer MM, Bagasra A (2013) Psychological research with Muslim Americans in the age of Islamophobia: Trends, challenges, and recommendations. Am Psychol 68: 134-144.

38. Awad GH (2010) The impact of acculturation and religious identification on perceived discrimination for Arab/Middle Eastern Americans. Cultur Divers Ethnic Minor Psychol 16: 59-67.

39. Aprahamian M, Kaplan DM, Windham AM, Sutter JA, Visser J (2011) The relationship between acculturation and mental health of Arab Americans. J Transcult Nurs 33: 80-92.

40. Hakim-Larson JH, Menna R (2016) Acculturation and enculturation: Ethnic identity socialization processes. In: Amer MM, Awad GH (Eds.) Handbook of Arab American psychology New York, NY: Routledge, pp: 34-47. 
Citation: Balesh C, Gamst G, Meyers LS, Karabetian AD, Elias C (2018) A Structural Model Predicting Arab American's Attitudes towards Mental Health Services from Ethnic Identity, Acculturation, and Spirituality. J Ment Disord Treat 4: 162. doi:10.4172/2471-271X.1000162

41. Amer MM, Awad GH (2016) Handbook of Arab American psychology. New York, NY: Routledge.

42. Hill PC, Pargament KI (2003) Advances in the conceptualization and measurement of religion and spirituality: Implications for physical and mental health research. Am Psychol 58: 64-74.

43. Keck LT (1989) Egyptian Americans in the Washington, DC area. Arab Studies Quarterly 11: 103-126.

44. Barry D, Elliott R, Evans EM (2000) Foreigners in a strange land: Self-construa and ethnic identity in male Arabic immigrants. J Immigr Health 2: 133-144.

45. Amer MM, Hovey JD, Fox CM, Rezcallah A (2008) Initial development of the Brief Arab Religions Coping Scale (BARCS). Journal of Muslim Mental Health 3: 69-88.

46. Read JG (2004) Family, religion, and work among Arab American women Journal of Marriage and Family 66: 1042-1050.

47. Padella Al, Heisler M (2010) The association of perceived abuse a discrimination after September 11, 2001, with psychological distress, level of happiness, and health status among Arab Americans. American Journal of Public Health 100 284-291.

48. Rousseau C, Hassan G, Moreau N, Thombs BD (2011) Perceived discrimination and its association with psychological distress among newly arrived immigrants before and after September 11, 2001. American Journal of Public Health 101 909-915

49. Ajrouch K (2007) Resources and well-being among Arab-American elders. J Cross Cult Gerontol 22: 167-182.

50. Reizian A, Meleis Al (1987) Symptoms reported by Arab-American patients on the Cornell Medical Index. Western Journal of Nursing Research 9: 368-384.

51. Eid $P$ (2003) The interplay between ethnicity, religion, and gender among second- generation Christian and Muslim Arabs in Montreal. Canadian Ethnic Studies 35: 30-60.

52. Amer MM, Kayyali, RA (2016). Religion and religiosity: Christian and Muslim faiths, diverse practices, and psychological correlates. In: Amer MM, Awad GH (eds.) Handbook of Arab American psychology; 48-62. New York, NY: Routledge.

53. Phinney JS, Ong AD (2007) Conceptualization and measurement of ethnic identity: Current status and future directions. Journal of Counseling Psychology 54: $271-281$.

54. Brown TA, Moore MT (2012) Confirmatory factor analysis. In: Hoyle RH (ed.) Handbook of structural equation modeling. New York, NY Guilford, pp: 361

55. Ryder AG, Alden LE, Paulhus DL (2000) Is acculturation unidimensional or bidimensional? A head-to-head comparison in the prediction of personality, self-identity, and adjustment. Journal of Personality and Social Psychology 79 : 49-65.

56. Ryder AG, Alden LE, Paulus DL, Dere J (2013) Does acculturation predict interpersonal adjustment? It depends upon who you talk to. International Journal of Intercultural Relations 37: 502-506.

57. Underwood LG, Teresi JA (2002) The daily spiritual experience and scale: Development, theoretical description, reliability, exploratory factor analysis, a preliminary construct validity using health-related data. Annals of Behavioral Medicine 24: 22-33.

58. Fischer EH, Farina A (1995) Attitudes toward seeking professional psychological help: A shortened form and considerations for research. Journal of College Student Development 3: 368-373.

59. Fischer EH, Turner JL (1970) Orientations to seeking professional help: Development and research utility of an attitude scale. J Consult Clin Psychol 35: 79-90.

60. Ægisdottir S, Gerstein LH (2009) Beliefs about psychological services (BAPS) Development and psychometric properties. Counselling Psychology Quarterly 22: $197-219$.

61. Reynolds WM (1982) Development of reliable and valid short forms of the Marlowe-Crowne Social Desirability Scale. Journal of Clinical Psychology 38: 119-125.

62. Coffman DL, MacCallum RC (2005) Using parcels to convert path analysis models into latent variable models. Multivariate Behav Res 40: 235- 259.
63. Kline RB (2015) Principles and practice of structural equation modeling (4thedn) Guilford Press, New York.

64. Bandalos DL (2002) The effects of item parceling on goodness-of-fit and parameter estimate bias in structural equation modeling. Structural Equation Modeling 9: 78-102.

65. Bandalos DL, Finney SJ (2001) Item parceling issues in structural equation modeling. In: Marcoulides GA, Schumacker RE (eds.) New developments and techniques in structural equation modeling, pp: 269-296. Mahwah, NJ: Erlbaum.

66. Little TD, Cunningham WA, Shahar G, Widaman KF (2002) To parcel or not to parcel: Exploring the question, weighing the merits. Structural Equation Modeling 9: 151-173

67. Little TD, Rhemtulla M, Gibson K, Schoemann AM (2013) Why the items versus parcels controversy need not be one. Psychological Methods 18: 285-300.

68. Matsunaga M (2008) Item parceling in structural equation modeling: A primer Communication Methods and Measures 2: 260-293.

69. Abe-Kim J, Gong F, Takeuchi D (2004) Religiosity, spirituality, and help-seeking among Filipino Americans: Religious clergy or mental health professionals? J Comm Psychol 32: 675-689.

70. Keyes K, Martins S, Hatzenbuehler M, Blanco C, Bates, et al. (2012) Menta health service utilization for psychiatric disorders among Latinos living the United States: The role of ethnic subgroup, ethnic identity, and language/social preferences. Soc Psychiatry Psychiatr Epidemiol 47: 383-394.

71. Kim BK, Omizo MM (2003) Asian cultural values, attitudes toward seeking professional psychological help, and willingness to see a counselor. Counseling Psychologist 31: 343-361.

72. Obasi EM, Leong FL (2009) Psychological distress, acculturation, and mental health-seeking attitudes among people of African descent in the United States: A preliminary investigation. Journal of Counseling Psychology 56: 227-238.

73. Faragallah MH, Schumm WR, Webb FJ (1997) Acculturation of Arab American immigrants: An exploratory study. Journal of Comparative Family Studies 28 182-203.

74. Jadalla A, Lee J (2012) The relationship between acculturation and genera healt of Arab Americans. J Transcult Nurs 23: 159-165.

75. Jadalla AA, Hattar M, Schubert CC (2015) Acculturation as a predictor of health promoting and lifestyle practices of Arab Americans: A descriptive study. J Cult Divers 22: 15-22.

76. Al Krenawi A, Graham JR (2011) Mental health help-seeking among Arab university students in Israel, differentiated by religion. Mental Health, Religion and Culture 14: 157-167.

77. Abu-Ras W, Gheith A, Cournos F (2008) The imam's role in mental health promotion: A study of 22 mosques in New York City's Muslim community. Journal of Muslim Mental Health 3: 155-176.

78. Al Krenawi A, Graham JR (1999) Gender and modern mental services/ traditional mental health utilization among Bedouin-Arab of the Negev. Culture, Medicine and Psychiatry 23: 219-243.

79. Aroian LA (1947) The probability function of the product of two normally distribute variables. Ann Math Statist 18: 265-271.

80. Bowen NK, Guo S (2012) Structural equation modeling. New York, NY: Oxford.

81. Dana RH (2000) Multicultural assessment principles, applications and examples Mahwah, NJ: Erlbaum.

82. Freedman LS, Schatzkin A (1992) Sample size for studying intermediate endpoints within intervention trials of observation studies. American Journal of Epidemiology 136: 1148-1159.

83. Gamst GC, Liang CTH (2013) A review and critique of multicultural competence measures: Toward a social justice-oriented health service delivery model. In: Paniagua FA, Yamada AM (eds.) Handbook of multicultural mental health: Assessment and treatment of diverse populations (2ndedn), San Diego, CA: Academic Press, pp: 547-569.

84. Gamst G, Dana RH, Der-Karabetian A, Kramer T (2001) Asian American mental health clients: Effects of ethnic match and age on global assessment an visitation. Journal of Mental Health Counseling 23: 57-71.

85. Meyers LS, Gamst G, Guarino AJ (2017) Applied multivariate research: Design 
Citation: Balesh C, Gamst G, Meyers LS, Karabetian AD, Elias C (2018) A Structural Model Predicting Arab American's Attitudes towards Mental Health Services from Ethnic Identity, Acculturation, and Spirituality. J Ment Disord Treat 4: 162. doi:10.4172/2471-271X.1000162

Page 9 of 9

and interpretation (3rdedn), SAGE Publisher, Thousand Oaks, California.

86. Sánchez LR, Atkinson DR (2009) The relationships between Mexican American acculturation, cultural values, gender, and help-seeking intentions. Journal of Counseling \& Development 87: 62-71.

87. Sobel ME (1982) Aysmptotic confidence intervals for indirect effects and their standard errors in structural equation models. In: N Tuma (eds) Sociological methodology. Jossey-Bass, San Francisco, California, pp: 159-186
88. Sobel ME (1986) Some new results on indirect effects in structural equation models. In: S Leinhardt (eds) Sociological methodology.American Sociological Association, Washington, DC.

89. Wang J, Wang X (2012) Structural equation modeling: Applications using Mplus West Sussex. Wiley Publisher, United Kingdom.

90. Zook A, Sipps GJ (1985) Cross-validation of a short form of the MarloweCrowne Social Desirability Scale. Journal of Clinical Psychology 41: 236-238. 